\title{
Structural Alterations of the Choroid Evaluated by Enhanced-Depth Imaging Optical Coherence Tomography in Patients with COVID-19
}

\section{Özkan KOCAMIŞ}

Ahi Evran Universitesi Tip Fakultesi

Emine Temel ( $\nabla$ emine912@hotmail.com )

Ahi Evran Universitesi Tip Fakultesi

Lokman HIZMALI

Ahi Evran Universitesi Tip Fakultesi

Nazife AŞIKGARIP

Ahi Evran Universitesi Tip Fakultesi

Kemal ÖRNEK

Ahi Evran Universitesi Tip Fakultesi

Fikriye Milletli Sezgin

Ahi Evran Universitesi Tip Fakultesi

Research article

Keywords: Choroidal vascularity index, COVID-19, coronavirus, enhanced depth imaging optical coherence tomography

Posted Date: October 29th, 2020

DOl: https://doi.org/10.21203/rs.3.rs-97433/v1

License: (9) This work is licensed under a Creative Commons Attribution 4.0 International License. Read Full License 


\section{Abstract}

Background: To assess alterations of choroid by enhanced depth imaging optical coherence tomography (EDI-OCT) in coronavirus disease 2019 (COVID-19).

Methods: Thirty-two patients with COVID-19 infection (group 1) and 34 healthy subjects (group 2) were included in this study. The choroidal thickness was measured at three points: Subfoveal, $1500 \mathrm{~mm}$ nasal from the fovea, and $1500 \mathrm{~mm}$ temporal from the fovea. Total choroidal area, luminal area, stromal area and choroidal vascular index (CVI) was measured by Image-J.

Results: In group 1, subfoveal, nasal, and temporal choroid thicknesses were thinner compared to group 2. However, there was no statistical significance ( $p=0.534, p=0.437$, and $p=0.077$, respectively). The mean total choroidal area, the mean stromal area, the mean luminal area, and the mean CVI were significantly decreased in group 1 ( $p<0.001, p=0.001, p=0.001$, and $p=0.003$; respectively).

Conclusions: Our results demonstrate that there may be choroidal vascular and stromal depletion in these patients.

\section{Background}

The novel coronavirus disease 2019 (COVID-19) is extremely contagious causing severe acute respiratory distress syndrome and can lead to death especially in patients with concomitant systemic disease [1]. The disease has rapidly become widespread, resulting in an epidemic throughout China, followed by a pandemic, an increasing number of cases in various countries throughout the whole World [2].

The exact pathophysiologic mechanism of COVID-19 infection remains stil largely unknown. It has been suggested that during the disease course, immune dysregulation, and the high level of proinflammatory cytokines could be the main cause of tissue injury [3]. In addition, some studies showed that vascular damage, thrombosis, and dysregulation of immune-mediated inflammation play an important role in the pathogenesis of severe COVID-19 infection [4].

COVID-19 infection has been shown to affect different parts of the body. Current studies on the ocular effects of COVID-19 infection are limited. As far as we know ophthalmological changes have been limited to external diseases such as conjunctivitis [5-7]. Furthermore, it was reported that ocular manifestations like retinitis, uveitis, and optic neuritis occured due to coronavirus infections in various animal models [8]. Casagrande et al. showed that viral ribonucleic acid is detectable in the retina of patients with COVID-19 infection [9].

Enhanced depth imaging optical coherence tomography (EDI-OCT) is a non-invasive imaging tool that enables to demonstrating retinal and choroidal structural alterations in many ocular and systemic conditions $[10,11]$. Since COVID-19 infection has been reported to cause vascular dysfunction and inflammation, we suppose that the disease may affect the choroid and its vascular structure. Therefore, 
the aim of our study was to assess the alterations in choroidal tissue by using EDI-OCT and Image- $J$ in eyes of patients with COVID-19 infection.

\section{Methods}

\section{Patient Selection}

This prospective, cross-sectional study included patients who were hospitalized for confirmed COVID-19 at the Kırşehir Ahi Evran University Training and Research Hospital. 32 eyes of 32 COVID-19 patients in (group 1) and 34 eyes of 34 patients in healty subjects (group 2) were included in the study. The right eye of each patient was included in the study. All patients in group 1 were positive for COVID-19 on real-time reverse transcriptase-polymerase chain reaction (RT-PCR) from nasopharyngeal swabs.

The study was performed in adherence to the tenets of the Declaration of Helsinki and was approved by the institutional review board at the Kırşehir Ahi Evran University School of Medicine. Each patient was informed about the aims and methods of the study and informed consent was obtained from all patients.

The criteria for exclusion from the study were determined as retinal diseases like retinal vascular occlusive disease, hypertensive retinopathy, diabetic retinopathy, central serous chorioretinopathy, agerelated macular degeneration, degenerative myopia, and previous vitreoretinal surgery.

Those with systemic diseasesas diabetes mellitus and systemic hypertension were not also included in the study. In addition, patients with poor EDI-OCT image quality due to severe corneal opacities or lens opacities were excluded from the study.

\section{Imaging and Image Analysis}

Slit-lamp biomicroscopy and EDI-OCT (Spectralis ${ }^{\circledR}$, Heidelberg Engineering Inc., Heidelberg, Germany) measurements were performed by the ophthalmologists wearing full protective equipment in group 1 . The same measurements were also performed for the eyes included in the control group.

Choroidal thickness was measured from the outer portion of the hyperreflective line, corresponding to the retinal pigment epithelium (RPE), to the inner surface of the sclera. The choroidal thickness measurements were made at the following three points: subfoveal, $1500 \mu \mathrm{m}$ nasal from the fovea, and $1500 \mu \mathrm{m}$ temporal from the fovea (Figure 1). All measurements were performed by the same experienced physician at the same time of the day to avoid the influence of diurnal variations.

Binarization of the choroidal area was performed with Image-J (Version 1.50a; National Institutes of Health, Bethesda, MD, USA) (Figure 2 and 3). $3000 \mu \mathrm{m}$ wide area with margins of $1500 \mu \mathrm{m}$ temporal to the fovea was chosen and borders set manually. The choroidal area was defined from the RPE to the chorioscleral border. The image was adjusted by the Niblack auto local threshold. The luminal area was determined with the threshold tool. The choroidal area, luminal area, and stromal area were calculated. The light pixels were admitted as the stromal area and the dark pixels as the luminal area [12]. The 
choroidal vascularity index $(\mathrm{CVI})$ was calculated as the ratio or proportion of the luminal area within the circumscribed subfoveal choroidal area

\section{Statistical Analysis}

All comparisons between groups were statistically analyzed using SPSS 11.5 (SPSS Inc., Chicago, IL, USA). The normality of all data was tested by the Kolmogorov-Smirnov test. The significance of the difference among all groups was investigated by a one way analysis of variance (ANOVA) and the Kruskal-Wallis test. Pairwise comparisons with the Tukey HSD and Bonferroni tests were used to evaluate which groups differed. Statistical significance was set at $p<0.05$.

\section{Results}

Among the patients with COVID-19 infection, 14 (43.7\%) of them were female, and the mean age was $35.9 \pm 21.6$ (range: $8-87$ ) years. Twenty $(58.8 \%$ ) of the control group were female and the mean age was $37.2 \pm 14.9$ (range: $10-63$ ) years. There was no statistically significant difference between the two groups in terms of age and gender $(p=0.667$ and $p=0.452$, respectively). Table-1 shows the demographic and clinical data of the study groups.

Among patients with COVID-19, seven (21.9\%) patients had pathological findings due to COVID-19 infection on computerized chest tomography. Two (28.6\%) patients, with pathological findings on chest tomography, had symptoms like cough and shortness of breath. In addition, among patients with COVID19, five (15.6\%) patients had abnormal laboratory findings as elevated C-reactive protein and reduced number of lymphocytes. None of the patients, both symptomatic/asymptomatic and those with positive chest tomography findings, had coexisting ocular symptoms or findings. There were no abnormalities of the ocular surface, anterior chamber or posterior segment at slit lamp examination.

Mean sub-foveal choroidal thickness was $311.21 \pm 74.10 \mu \mathrm{m}$ in group 1 and $322.91 \pm 77.56 \mu \mathrm{m}$ in group 2. Mean choroidal thickness at $1500 \mu \mathrm{m}$ nasal to the fovea was $260.31 \pm 80.62 \mu \mathrm{m}$ in group 1 and $274.29 \pm 64.21 \mu \mathrm{m}$ in group 2. Mean choroidal thickness at $1500 \mu \mathrm{m}$ temporal to the fovea was $261.71 \pm$ $74.27 \mu \mathrm{m}$ in group 1 and $297.73 \pm 87.57 \mu \mathrm{m}$ in group 2. In group 1, subfoveal, $1500 \mu \mathrm{m}$ nasal, and $1500 \mu \mathrm{m}$ temporal choroid thicknesses were thinner than in healthy subjects. There was no statistically significant difference between the two groups $(p=0.534, p=0.437$, and $p=0.077$, respectively). The distribution of choroidal thickness changes among groups is shown in Fig. 4.

According to measurements made with Image-J, the mean total choroidal area was $0.540 \pm 0.17 \mathrm{~mm}^{2}$ in group 1 and $0.957 \pm 0.21 \mathrm{~mm}^{2}$ in group 2 . When the measurements between group 1 and group 2 were compared, there was a statistically significant difference in terms of total choroidal area $(p<0.001)$. The mean stromal area was $0.164 \pm 0.05 \mathrm{~mm}^{2}$ in group 1 and $0.229 \pm 0.08 \mathrm{~mm}^{2}$ in group 2 . It was observed that the mean stromal area decreased statistically significantly in group 1 compared to the control group $\left(p=0.001\right.$ ). The mean luminal area was $0.376 \pm 0.15 \mathrm{~mm}^{2}$ in group 1 and $0.727 \pm 0.16 \mathrm{~mm}^{2}$ in group 2 . According to these measurements, the average luminal area was statistically significantly lower in group 
1 than in the control group $(p=0.001)$. The mean CVI was $67.91 \pm 0.11$ in group 1 and $76.11 \pm 0.07$ in group 2. It was also noted that the mean CVI was statistically significantly lower in group 1 than in healthy subjects $(p=0.003)$. The distribution of CVI changes among groups is shown in Figure-5. Table- 2 lists the choroidal thickness and CVI changes in patients with COVID-19 and control groups.

\section{Discussion}

Coronavirus has been shown to manifest in other parts of the human body including the gastrointestinal system and the eye besides the respiratory system $[13,14]$. Most of the clinical studies about coronavirus have focused on the respiratory system because of its life-threatening nature. Evaluation of other organ systems should be considered and this may provide valuable information so as to uncover the unknown mechanisms of tissue injury.

Ocular involvement in COVID-19 patients is limited to the conjunctiva and tear film layer, as reported in previous studies $[5,6,15]$. It has been shown that viral ribonucleic acid can be detected in the retina of infected people [9]. In a study by Seah et al., coronaviruses were shown to be capable of producing various ocular manifestations from anterior segment pathologies like conjunctivitis and anterior uveitis to vision-threatening conditions like retinitis and optic neuritis [8].

The factors that trigger severe disease in individuals infected with COVID-19 are not completely understood. It has been shown that hyper-inflammation and coagulopathy contribute to disease severity and death in patients with COVID-19 [16]. In addition, clinical studies suggest that severe COVID-19 infection reflects a confluence of vascular dysfunction and disruption in thrombosis mechanisms [4].

The choroid is the vascular part of the eye and has an important role in the pathogenesis of several ocular diseases. The choroidal circulation is a dense network of capillaries located behind the RPE cell layer. The choriocapillaris which forms the innermost layer of the choroid is the fundamental blood supply to the outer retina. Because of the high metabolic demand of the photoreceptor layer, the choroid receives the plurality $(65-85 \%)$ of the blood that is supplied to the retinal structures [17]. Impaired choroidal blood flow is associated with several ocular diseases, such as glaucoma, retinitis pigmentosa, degenerative myopia and age-related macular degeneration. Histological analysis has shown that changes in the choroidal interstitial stroma may occur in eyes with age-related macular degeneration due to edema, fibrosis, and inflammation with cellular infiltration [18].

In current study, we provide for the first time evidence of choriocapillaris ischemia in eyes of patients with COVID-19 infection. We compared the luminal and stromal area of the choroid in patients with COVID-19 and healthy subjects by the binarization technique with Image-J. Our findings showed that the mean total choroidal, the mean luminal, and the mean stromal areas were statistically decreased in eyes of patients with COVID-19 when compared to healthy subjects.

Choroidal thickness is a parameter that varies substantially both in healthy and in pathological conditions. It decreases from the macula to the periphery and is at its maximum subfoveally. Choroidal 
thickness is not a true representative of the entire choroidal vasculature as an objective marker. Measuring CVI enables us to have information about both vascular and stromal components of the choroid [19]. Xin et al. Reported that CVI was shown to be independent of systemic and ocular factors like age, axial length, intraocular pressure, or systolic blood pressure [20]. However, choroidal thickness may vary depending on these factors. In a study by Xin et al., the mean value of CVI was reported as $70.12 \%$ for healthy subjects [20]. In our study, this ratio was $76.11 \%$ in controls. Agarwal et al. Found the subfoveal CVI as $65.61 \%$ in their study by including 345 eyes of healthy subjects with an average age of 61 years [21]. In our study, we found CVI as $76.11 \%$, but the average age of our control group was 37 years. Some studies purposed to determine normative values for CVI in healthy people and these studies investigated whether there is an age-related change in CVI value [21, 22]. Jaeryung et al. Showed no significant correlations of CVI with age [22]. In contrast, Ruiz-Medrano et al. reported that CVI to be significantly higher in the group with subjects under 18 years of age compared with the group of older people [23].

Some reports have been published regarding $\mathrm{CVI}$ and its implementations in the evaluation, diagnosis, and treatment of retinochoroidal diseases such as central serous chorioretinopathy, polypoidal choroidal vasculopathy, panuveitis, and diabetic retinopathy [24-28]. Agrawal et al. assessed CVI in people with posterior uveitis and panuveitis and they showed an increased CVI, which decreased after follow-up period [26]. Some choroidal changes such as decreased CVI were also reported in eyes with serpiginous choroiditis [28]. Shulin et al. demonstrated a lower CVI during the active period of Vogt-Koyanagi-Harada Disease and decreased CVI during the active phase were because of choroidal stromal edema and infiltration by inflammatory cells [29].

In our study, we observed that the average CVI value decreased in patients with COVID-19 infection compared to healthy subjects. According to our hypothesis, it is possible that vascular damage, hypercoagulability, and hyper-inflammation factors, which have been shown to be involved in the pathogenesis of COVID-19 infection, might have led to ischemia of choriocapillaris and decreased the $\mathrm{CVI}$. In addition, the reduction in the luminal area, stromal area, and CVI revealed by Image-J might be explained by the secondary result of the lack of oxygen demand.

We also compared choroidal thickness changes between the patients with COVID-19 and the control group. The subfoveal, $1500 \mu \mathrm{m}$ nasal, and $1500 \mu \mathrm{m}$ temporal choroid thickness were thinner in patients with COVID-19 than in healthy subjects. Although the choroidal thickness was decreased at all points, as $\mathrm{CVI}$ in patient group, we could not detect a statistically significant difference.

Limitations of our study include a relatively small sample size and absence of detailed ocular examinations owing to the logistical challenges of managing the COVID-19 patients. Binarization of choroidal images was performed only in the right eye of each participant, therefore inter-eye differences might have an effect on the results.

\section{Conclusions}


This is the first study to show impairment of the choriocapillaris in patients with COVID-19 compared to healthy subjects. Additionally, our findings indicate that there may be choroidal vascular and stromal depletion in patients with COVID-19. Further studies with larger sample size are needed to clarify the choroidal structural and vascular changes and determine the ocular blood flow in patients with COVID-19.

\section{Abbreviations}

COVID-19

novel coronavirus disease 2019

\section{EDI-OCT}

Enhanced depth imaging optical coherence tomography

RT-PCR

Real-time reverse transcriptase-polymerase chain reaction

CVI

Choroidal vascularity index

ANOVA

One way analysis of variance

\section{Declarations}

Ethics approval and consent to participate: The study was performed in adherence to the tenets of the Declaration of Helsinki and was approved by the institutional review board at the Kırşehir Ahi Evran University School of Medicine. Each patient was informed about the aims and methods of the study and informed consent was obtained from all patients. Written informed consent for participation in the study was obtained where participants are children (under 16 years old) from their parent or guardian.

Consent for publication: Each patient was informed about the aims and methods of the study and informed consent was obtained from all patients.

Availability of data and materials: Not available.

Competing interests: There is no competing interest.

Funding: There is no source of funding.

Authors' contributions: ÖK, ET, NA, and KÖ conceived of the presented idea and planned the study. ÖK, ET, NA, and KÖ carried out the measurements and analysis. ÖK, ET, NA, and KÖ wrote the manuscript with support from LH and FMS. All authors discussed the results and contributed to the final manuscript.

Acknowledgments: Not applicable

\section{References}


1. Lai CC, Shih TP, Ko WC, et al. Severe acute respiratory syndrome coronavirus 2 (SARS-CoV-2) and coronavirus disease-2019 (COVID-19): the epidemic and the challenges. Int J Antimicrob Agents. 2020;55(3):105924.

2. European Centre for Disease Prevention and Control. Geographical distribution of 2019-nCov cases. Available from: URL: https://www.ecdc.europa.eu/en/geographical-distribution-2019-ncov-cases. Accessed, January 26, 2020.

3. Tufan A, Avanoğlu Güler A, Matucci-Cerinic M. COVID-19, immune system response, hyperinflammation and repurposing antirheumatic drugs. Turk J Med Sci. 2020;50(SI-1):620-32.

4. Leisman DE, Deutschman CS, Legrand M. Facing COVID-19 in the ICU: vascular dysfunction, thrombosis, and dysregulated inflammation. Intensive Care Med. 2020;46(6):1105-8.

5. Wu P, Duan F, Luo C, et al. Characteristics of Ocular Findings of Patients With Coronavirus Disease 2019 (COVID-19) in Hubei Province, China. JAMA Ophthalmol. 2020;138(5):575-8.

6. Chen L, Liu M, Zhang Z, et al. Ocular manifestations of a hospitalized patient with confirmed 2019 novel coronavirus disease. $\mathrm{Br} J$ Ophthalmol. 2020;104(6):748-51.

7. Sommer A. Humans, viruses, and the eye-an early report from the COVID-19 front line. JAMA Ophthalmol. 2020;138(5):578-9.

8. Seah I, Agrawal R. Can the Coronavirus Disease 2019 (COVID-19) Affect the Eyes? A Review of Coronaviruses and Ocular Implications in Humans and Animals. Ocul Immunol Inflamm. 2020;28(3):391-5.

9. Casagrande M, Fitzek A, Püschel K, et al Schultheiss M. Detection of SARS-CoV-2 in Human Retinal Biopsies of Deceased COVID-19 Patients. Ocul Immunol Inflamm. 2020;1-5.

10. Kurup SP, Khan S, Gill MK. Spectral domain optical coherence tomography in the evaluation and management of infectious retinitis. Retina. 2014;34(11):2233-41.

11. Marinho PM, Marcos AAA, Romano AC, et al. Retinal findings in patients with COVID-19. Lancet. 2020;395(10237):1610.

12. Sonoda S, Sakamoto T, Yamashita T, et al. Choroidal structure in normal eyes and after photodynamic therapy determined by binarization of optical coherence tomographic images. Invest Ophthalmol Vis Sci. 2014;55(6):3893-9.

13. Loon S-C, Teoh SCB, Oon LLE, et al. The severe acute respiratory syndrome coronavirus in tears. British J Ophthalmol. 2004;88(7):861-3.

14. Yeo C, Kaushal S, Yeo D. Enteric involvement of coronaviruses: is faecal \& oral transmission of SARSCoV-2 possible? Lancet Gastroenterol Hepatol. 2020;5(4):335-7.

15. Seah IYJ, Anderson DE, Kang AEZ, et al. Assessing viral shedding and infectivity of tears in coronavirus disease 2019 (COVID-19) patients. Ophthalmology. 2020;127(7):977-9.

16. Merad M, Martin JC. Pathological inflammation in patients with COVID-19: a key role for monocytes and macrophages. Nat Rev Immunol. 2020;20(6):355-62. 
17. Kolb H. Simple Anatomy of the Retina. In: Kolb H, Fernandez E, Nelson R. Webvision: The Organization of the Retina and Visual System. Editors: Salt Lake City UT; 1995.

18. McLeod DS, Grebe R, Bhutto I, et al. Relationship between RPE and choriocapillaris in age-related macular degeneration. Invest Ophthalmol Vis Sci. 2009;50(10):4982-91.

19. Iovino C, Pellegrini M, Bernabei F. Bet al. Choroidal Vascularity Index: An In-Depth Analysis of This Novel Optical Coherence Tomography Parameter. J Clin Med. 2020;9(2):595.

20. Wei X, Sonoda S, Mishra C, et al. Comparison of Choroidal Vascularity Markers on Optical Coherence Tomography Using Two-Image Binarization Techniques. Invest Ophthalmol Vis Sci. 2018;59(3):1206-11.

21. Agrawal R, Gupta P, Tan K-A, et al. Choroidal vascularity index as a measure of vascular status of the choroid: measurements in healthy eyesfrom a population-based study. Sci Rep. 2016;6:21090.

22. Oh J, Baik DJ, Ahn J. Inter-relationship between retinal and choroidal vasculatures using optical coherence tomography angiography in normal eyes. Eur J Ophthalmol. 2020;30(1):48-57.

23. Ruiz-Medrano J, Ruiz-Moreno JM, Goud A, et al. Age-related changes in choroidal vascular density of healthy subjects based on image binarization of swept-source optical coherence tomography. Retina. 2018;38(3):508-15.

24. Singh SR, Vupparaboina KK, Goud A, et al. Choroidal imaging biomarkers. Surv Ophthalmol. 2019;64(3):312-33.

25. Wei X, Ting DSW, Ng WY, et al. Choroidal vascularity index: a novel optical coherence tomography based parameter in patients with exudative age-related macular degeneration. Retina. 2017;37(6):1120-5.

26. Agrawal R, Salman M, Tan K-A, et al. Choroidal vascularity index (CVI)-a novel optical coherence tomography parameter for monitoring patients with panuveitis? PLoSOne. 2016;11(1):e0146344.

27. Agrawal R, Li LKH, Nakhate V, et al. Choroidalvascularityindex in Vogt-Koyanagi-Harada disease: an EDI-OCT derived tool for monitoring disease progression. Trans Vis Sci Tec. 2016;5(4):7.

28. Agarwal A, Agrawal R, Khandelwal N, et al. Choroidal Structural Changes in Tubercular Multifocal Serpiginoid Choroiditis. Ocul Immunol Inflamm. 2018;26(6):838-44.

29. Liu S, Du L, Zhou Q, et al. The Choroidal Vascularity Index Decreases and Choroidal Thickness Increases in Vogt-Koyanagi-Harada Disease Patients During a Recurrent Anterior Uveitis Attack. Ocul Immunol Inflamm. 2018;26(8):1237-43.

\section{Tables}




\begin{tabular}{|c|c|c|}
\hline & Group 1 & Group 2 \\
\hline \multicolumn{3}{|l|}{ Patients } \\
\hline n (\%) & $32(48.5)$ & $34(51.5)$ \\
\hline \multicolumn{3}{|l|}{ Eyes } \\
\hline $\mathrm{n}(\%)$ & $32(48.5)$ & $34(51.5)$ \\
\hline Female n (\%) & $14(43.7)$ & $20(58.8)$ \\
\hline Male n (\%) & $18(56.2)$ & $14(41.2)$ \\
\hline Meanage (years) $\pm S D$ & $35.9 \pm 21.6$ & $37.2 \pm 14.9$ \\
\hline (Range) & $(8-87)$ & $(10-63)$ \\
\hline
\end{tabular}

Table 2: Choroidal structural characteristics

\begin{tabular}{|llll|}
\hline $\begin{array}{l}\text { Variables } \\
(\text { Mean } \pm \text { SD })\end{array}$ & Group 1 & Group 2 & p-value \\
\hline $\begin{array}{l}\text { Sub-foveal choroidal thickness }(\mu \mathrm{m}) \\
\text { Choroidal thickness at } 1500 \mu \mathrm{m} \text { nasal to the fovea }(\mu \mathrm{m})\end{array}$ & $260.31 \pm 80.62$ & $274.29 \pm 64.21$ & 0.437 \\
\hline $\begin{array}{l}\text { Choroidal thickness at } 1500 \mu \mathrm{m} \text { temporal to the fovea } \\
(\mu \mathrm{m})\end{array}$ & $261.71 \pm 74.27$ & $297.73 \pm 87.57$ & 0.077 \\
\hline $\begin{array}{l}\text { Total choroidal area }\left(\mathrm{mm}^{2}\right) \\
\text { Stromal area }\left(\mathrm{mm}^{2}\right)\end{array}$ & $0.540 \pm 0.17$ & $0.957 \pm 0.21$ & $<0.001^{*}$ \\
\hline Luminal area $\left(\mathrm{mm}^{2}\right)$ & $0.164 \pm 0.05$ & $0.229 \pm 0.08$ & $0.001^{*}$ \\
\hline CVI $(\%)$ & $0.376 \pm 0.15$ & $0.727 \pm 0.16$ & $0.001^{*}$ \\
\hline SD: Standard deviation; *: Statistically significant $\mathrm{p}$ values; CVl: Choroidal vascularity index & \\
\hline
\end{tabular}

\section{Figures}




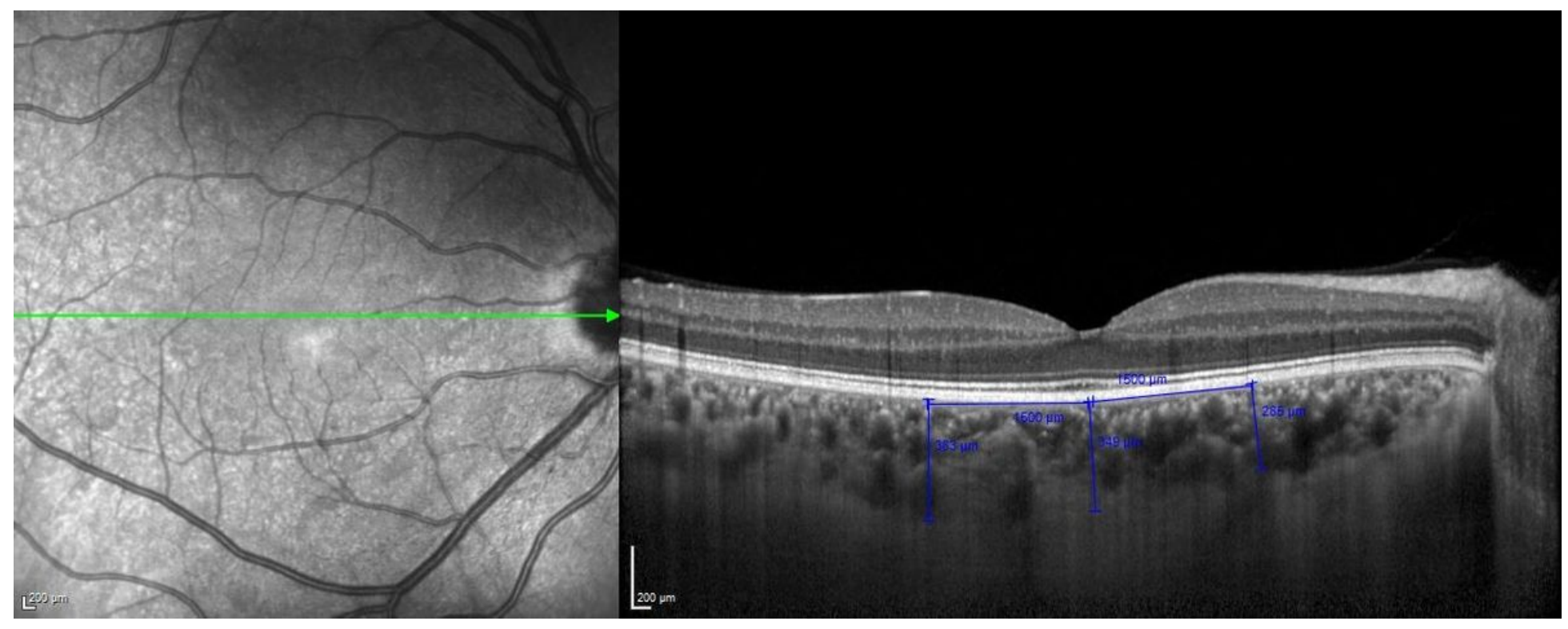

Figure 1

Choroidal thickness measurements were made at the following three points: subfoveal, $1500 \mu \mathrm{m}$ nasal from the fovea, and $1500 \mu \mathrm{m}$ temporal from the fovea

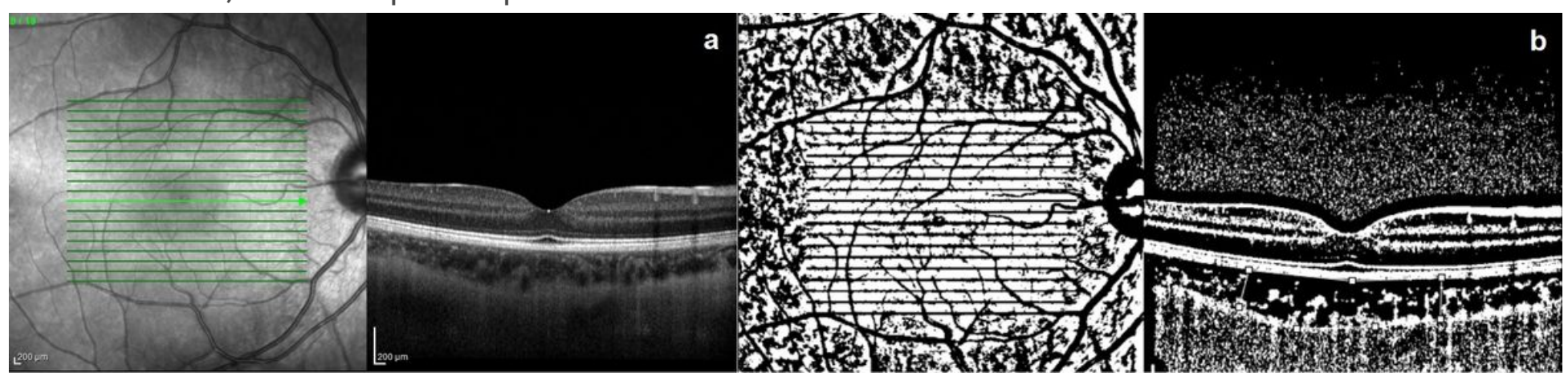

Figure 2

a: EDI-OCT image of theeye of a patient with COVID-19 infection b: Converted binary image using Image-J with the area of interest in the choroid demarcated with a white line. The choroidal area was measured at approximately $3000 \mu \mathrm{m}$ wide with the margins of $1500 \mu \mathrm{m}$ nasal and $1500 \mu \mathrm{m}$ temporal from the foveal center.

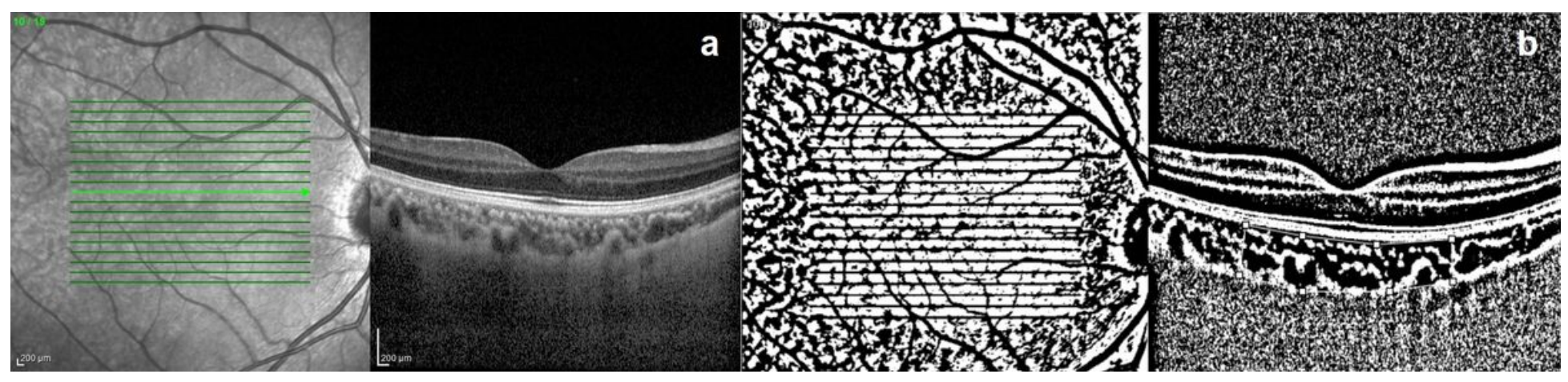

Figure 3 
a: EDI-OCT image of the eye of a healthy subject b: Converted binary image using Image-J with the area of interest in the choroid demarcated with a white line. The choroidal area was measured at approximately $3000 \mu \mathrm{m}$ wide with the margins of $1500 \mu \mathrm{m}$ nasal and $1500 \mu \mathrm{m}$ temporal from the foveal center.

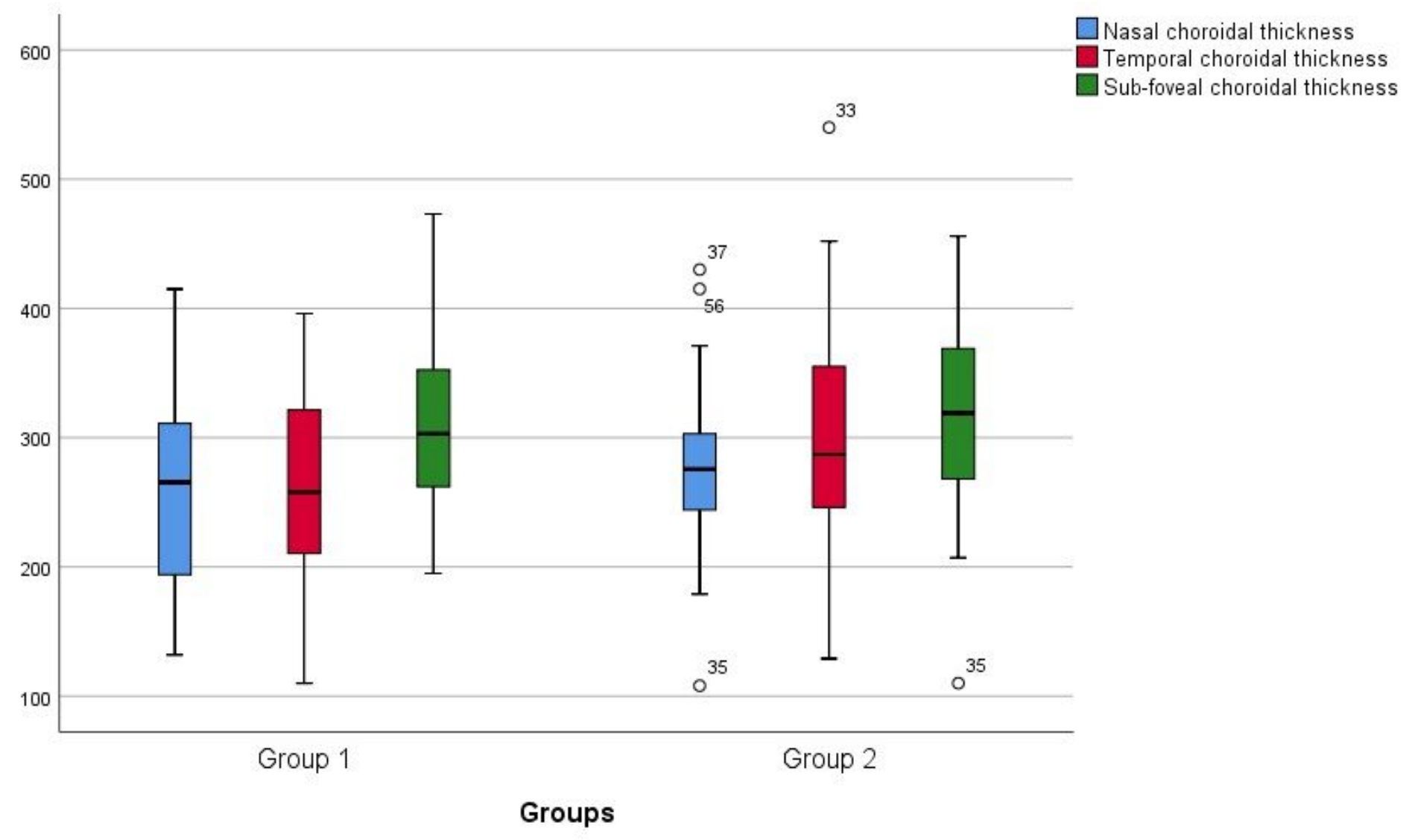

\section{Figure 4}

The distribution of choroidal thickness changes among groups 


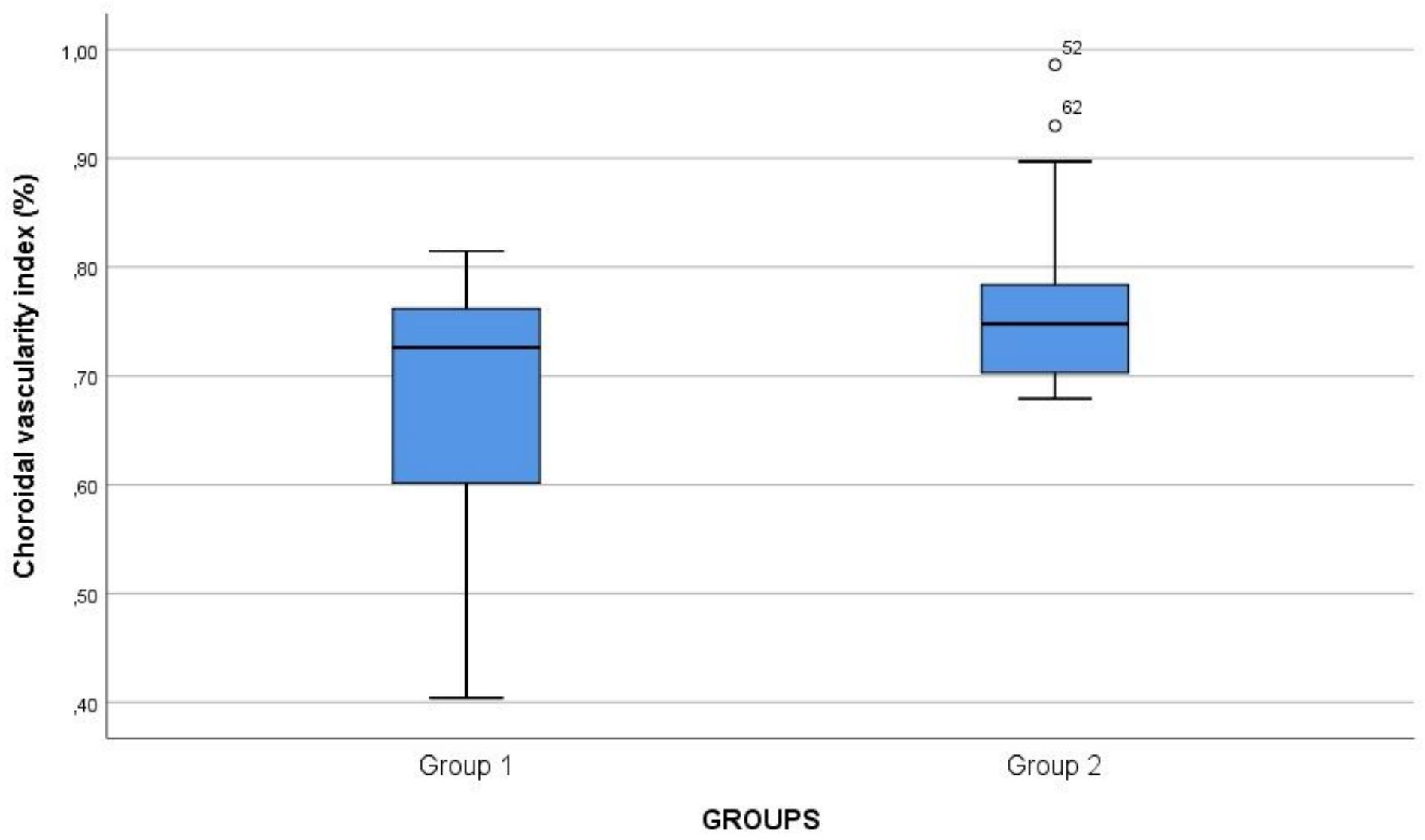

Figure 5

The distribution of CVI changes among groups

\section{Supplementary Files}

This is a list of supplementary files associated with this preprint. Click to download.

- STROBEchecklistconferenceabstractDRAFT.pdf 